Chirurgia (2018) 113: 503-515

No. 4, July - August

Copyright@ Celsius

http://dx.doi.org/10.21614/chirurgia.113.4.503

\title{
Prognostic Factors Analysis for Colon Cancer with Lymph Node Negative
}

\author{
Ionuț Vîlcea', Benoit Romain², Serge Rohr², Traean Burcoș ${ }^{1}$ \\ 'Department of General Surgery, Colțea Clinical Hospital, Carol Davila University of Medicine and Pharmacy, Bucharest, România \\ 2Department of General and Digestiv Surgery, Hautepierre Hospital, Les Hôpitaux Universitaires de Strasbourg, Strasbourg, France
}

Corresponding author:

Ionuț Vîlcea, MD, PhD Student

Colțea Clinical Hospital

General Surgery Department 1

I.C. Brătianu street, sector 3, 030171 ,

Bucharest, Romania

E-mail: valceaionut@yahoo.com
Received: 10.05 .2018

Accepted: 14.07.2018

\section{Rezumat \\ Analiza factorilor de prognostic pentru tumorile de colon cu ganglioni negativi}

Scop: S-au analizat factorii de prognostic cu risc crescut şi importanța lor privind riscul de recădere în cancerul de colon stadiul I şi II conform clasificării TNM ediția 8, 2017.

Metode: Analiza retrospectivă privind impactul factorilor de prognostic pentru pacienții cu risc crescut de recidivă în stadiul I şi II. S-a studiat un lot de 99 de pacienți cu tumori $\mathrm{T}_{2}, \mathrm{~T}_{3}, \mathrm{~T}_{4}$ care au suferit o rezecție curativă şi care pot prezenta sau nu indicație pentru chimioterapie adjuvantă pe baza factorilor histoprognostici şi biomarkerilor moleculari.

Rezultate: La regresia Cox univariată se evidențiază următoarele: sexul masculin este un factor de risc pentru recăderea bolii $(\mathrm{HR}=5,53, \mathrm{p}<0,05, \mathrm{IC} 95 \%=1,29$ la 23,73). Deşi cu efect statistic nesemnificativ, tumorile $\mathrm{T}_{4}$ par a fi asociate cu un prognostic nefavorabil în ceea ce priveşte recăderea bolii $(\mathrm{HR}=2,56, \mathrm{p}=0,06$, IC95\% $=0,94$ la 6,99) în raport cu tumorile $\mathrm{T}_{2}$ şi T3. Pacienții cu d'MMR (MSI - H) par a avea o evolutie mai favorabilă în raport cu pacienții cu p'MMR (MSS/MSI-L) - HR (d'MMR vs p'MMR) = 0,19, IC95\% $=0,02$ la 1,61, $(\mathrm{p}=0,13)$.

Concluzii: Considerăm că ar fi util ca MSS/MSI să fie analizați sistematic, datele noastre sugerând un răspuns mai bun al pacienților cu d'MMR la chimioterapia adjuvantă. Regresia Cox multivariată nu a identificat factori de risc de recadere independenți.

Cuvinte cheie: cancer colorectal, factor de prognostic, ganglioni limfatici, chimioterapie 


\begin{abstract}
Purpose: The analysis of high risk relapse prognosis factors and their importance regarding recurrence risk for stage I and II colon cancer, according to TNM classification $8^{\text {th }}$ edition, 2017.

Material and Method: We performed a retrospective analysis regarding the impact of prognosis factors for patients with high recurrence risk in stages I and II. We studied 99 patients with $\mathrm{T}_{2}$, $\mathrm{T}_{3}$ and $\mathrm{T}_{4}$ tumors who suffered a curative resection and whom may or may not present indication for adjuvant chemotherapy according to histoprognostic factors and molecular biomarkers.

Results: We performed a univariate Cox regression which highlighted that male sex is a risk factor for disease relapse $(\mathrm{HR}=5.53, \mathrm{p}<0.05$, IC95\% = 1.29 to 23.73). Although with a low statistical significance effect, $\mathrm{T}_{4}$ tumors seems to be associated with a poor prognosis regarding disease relapse $(\mathrm{HR}=2.56, \mathrm{p}=0.06, \mathrm{IC} 95 \%=0.94$ to 6.99$)$ compared to $\mathrm{T}_{2}$ and $\mathrm{T}_{3}$ tumors. Patients with d'MMR (MSI-H) seem to have a more favorable evolution compared to patients with p'MMR (MSS/MSI-L) - HR (d'MMR vs p'MMR) $=0.19$, IC95\% $=0.02$ to $1.61, p=0.13$.

Conclusions: We believe that it would be useful for MSS / MSI to be systematically analyzed, our data suggesting a better response of d'MMR patients to adjuvant chemotherapy. The multivariate Cox regression did not identify independent risk factors of relapse.
\end{abstract}

Key words: colorectal cancer, prognosis factor, lymph node, chemotherapy

\section{Introduction}

Colorectal cancer represents one of the most frequent types of cancer with approximately 1,36 million new cases every year around the world (1)

For stage I and II tumours (according to the TNM classification, 8th edition, 2017) (2), typically, initial surgery may be considered curative (3-6)

In light of recent research the indication for adjuvant chemotherapy is considered for patients thought to have associated high risk factors even if they do not present positive nodes or metastases at the time of the initial diagnosis (7-12).

Prognostic factors that can highlight the need for adjuvant chemotherapy or targeted therapies and those on which international recommendations or expert opinions are based include:: high-risk stage II, T4 tumour, poor tumour differentiation, intestinal occlusion or perforation, positive resection margins, preoperative positive CEA (carcinoembryonic antigen), tumour location, vascular-lymphatic and perineural invasion, inadequate lymph node resection ( $<12$ nodes) $(7,13-17)$.

Relatively recent, the identification of recurrence risk biomarkers in stage II and even I, by using MMR (mismatch repair) and MSI (microsatelite instability), as well as other biomarkers that have been mesured systematically and have brought benefit by associating adjuvant chemotherapy to the management of risk patients $(4,18,19)$.

For patients with stage II colorectal cancer, the association of adjuvant chemotherapy remains controversial, so the need for applying standardized protocols according to each prognosis factor is recommended $(3,5,13,20)$.

Literature data suggest that overall survival prognosis for tumors located on the left colon is better than for those located on the right colon (21).

\section{Material and Method}

This is a retrospective, non-randomized, observational study, based on the analysis of data provided from the medical archive of the Service de Chirurgie General et Digestive, Hopital de Hautpierre, Strasbourg and it includes patients who suffered a surgical intervention in the period august 2003 to November 2012 and followed up until September 2017, diagnosed with colon cancer 
with respect to the recommendations of the Ethical Committee of the Hospital.

The study was performed on a sample of 99 patients with surgery for colon cancer (excluding rectal cancer), stage I and II, respectively $\mathrm{T}_{2}, \mathrm{~T}_{3}, \mathrm{~T}_{4}$ tumors, negative lymph nodes,adenocarcinomas, no metastases or other cancers in their personal history, with lymphadenectomy (at least 12 resected nodes), negative resection margins (R0), with regular follow-ups in surgery, oncology and gastroenterology departments, as well as the general practitioner surgeries.

Exclusion criteria such as the World Health Organization (WHO) performance status, past medical history (except for a personal history of cancer), age, gender, occlusion or perforation of tumors have not been taken into consideration.

We used for statistical analysis parameters as: patient name, sex, birth date, surgery date, type of surgery, histopathological examination report, date of last follow-up, surveillance period, possible recurrences and the date they were diagnosticated, treatment, tumor grading, CEA, presence/absence of vascular emboli, tumors with intestinal occlusion or perforation at the time of diagnosis and patient death.

Patients who had chemotherapy (according to recurrence risk criteria) were followed, and a part of the patients also received specific biomarker dosage.

On the basis of the enrolled patients, statistical correlations were made regarding the relapse-free period, relapse meaning the emersion of signs of disease (recurrence, metastases) and the risk of relapse.

Statistical correlations were performed regarding plenty general aspects of the studied population which show the characteristics of the studied sampled, as well as how these can influence indirectly the survival rate, but cannot influence directly the risk of recurrence:

- Male/Female ratio;

- Recurrence according to stage;

- Type of surgery according to tumor location;

- Adjuvant chemotherapy (yes/no).

The proper analysis of risk factors debated in the literature consists in the study of impact for each regarding recurrence risk:

- Pre-op CEA;

- Presence of vascular emboli;

- Tumor grading;

- Type of surgery according to tumor location;

- The presence of occlusion at the time of diagnosis;

- The presence of perforation at the time of diagnosis;

- Correlations involving molecular biomarkers.

The follow-up period was calculated differently, according to the presence/absence of relapse; for patients with relapse it represented de difference (in months) between the date of surgery and the date we have discovered that the patient had relapse; for patients with recurrence it was the censorship period - that is the difference between the date of surgery and time of the last follow-up.

The analysis of the influence of possible factors on end-points was made in 2 stages: a univariate analysis for which the Kaplan-Meier method and a Cox univariate regression were used and a multivariate analysis for which a Cox multivariate regression was used.

The data is represented in the form of Mean $\pm \mathrm{SD}=$ Standard Deviation (Range) or Median (Range) for continuous variables and in the form of $\mathrm{Nr}(\%)$ for categorical variables.

\section{Copyright data}

For the statistical analysis we used $R$ version 3.4.4 (C) R Core Team (2018). R: A language and environment for statistical computing. $R$ Foundation for Statistical Computing, Vienna, Austria. URL: http://www.R-project.org with the specific package for survival analysis survminer (C) - Alboukadel Kassambara and Marcin Kosinski (2018).survminer: Drawing Survival Curves using 'ggplot2'. R package verson 0.4.2.https://CRAN.R-project.org/package $=$ survminer and SAS University Edition verson 9.4 (C) SAS Institute, Cary, NC.

\section{Results}

A descriptive analysis of the variables pursued in the study (see Table 1).

Data are presented as Mean $\pm \mathrm{SD}=$ 
Table 1. The descriptive analysis of the data about patients

\begin{tabular}{|c|c|}
\hline Variable & Patients Lot $(n=99)$ \\
\hline$\overline{\text { Age }- \text { Mean } \pm \text { SD (Range) }}$ & $67.74 \pm 11.62$ (34 to 91$)$ \\
\hline \multicolumn{2}{|l|}{ Sex } \\
\hline $\mathrm{M}-\mathrm{Nr}(\%)$ & $65(65.66)$ \\
\hline $\mathrm{F}-\mathrm{Nr}(\%)$ & $34(34.34)$ \\
\hline \multicolumn{2}{|l|}{ Tumor Location } \\
\hline Left $-\mathrm{Nr}(\%)$ & $45(45.45)$ \\
\hline Right - Nr (\%) & $54(54.55)$ \\
\hline \multicolumn{2}{|l|}{ Stage T } \\
\hline $\mathrm{T} 2-\mathrm{Nr}(\%)$ & $21(21.21)$ \\
\hline T3 - Nr (\%) & $66(66.67)$ \\
\hline $\mathrm{T} 4-\mathrm{Nr}(\%)$ & $12(12.12)$ \\
\hline \multicolumn{2}{|l|}{ Grading } \\
\hline $\mathrm{G} 1-\mathrm{Nr}(\%)$ & $44(44.44)$ \\
\hline $\mathrm{G} 2-\mathrm{Nr}(\%)$ & $23(23.23)$ \\
\hline G3 - Nr (\%) & $32(32.32)$ \\
\hline \multicolumn{2}{|l|}{ Adjuvant Chemotherapy } \\
\hline Yes - Nr (\%) & $22(22.22)$ \\
\hline No - Nr (\%) & $77(77.78)$ \\
\hline \multicolumn{2}{|l|}{ Perforation } \\
\hline Yes - Nr (\%) & $16(16.16)$ \\
\hline No - Nr (\%) & $83(83.84)$ \\
\hline \multicolumn{2}{|l|}{ Occlusion } \\
\hline Yes - Nr (\%) & $16(16.16)$ \\
\hline No - Nr (\%) & $83(83.84)$ \\
\hline \multicolumn{2}{|l|}{ Relapse } \\
\hline Yes - Nr (\%) & $22(22.22)$ \\
\hline No - Nr (\%) & 77 (77.78) \\
\hline \multicolumn{2}{|l|}{ Follow-up Period (In Months) } \\
\hline With Relapse - Median (Range) & 22.50 (1 to 71$)$ \\
\hline Censored - Median (Range) & 41 (1 to 112$)$ \\
\hline Overall - Median (Range) & 36 (1 to 112$)$ \\
\hline \multicolumn{2}{|l|}{ MMR Status } \\
\hline p MMR - Nr (\%) & $15(15.15)$ \\
\hline d MMR - Nr (\%) & $11(11.11)$ \\
\hline $\mathrm{N} / \mathrm{A}-\mathrm{Nr}(\%)$ & $73(73.74)$ \\
\hline \multicolumn{2}{|l|}{ Vascular Emboli } \\
\hline Yes - Nr (\%) & $10(10.10)$ \\
\hline No - Nr (\%) & $89(89.90)$ \\
\hline \multicolumn{2}{|l|}{ Deceased } \\
\hline Yes - Nr (\%) & $3(3.03)$ \\
\hline No - Nr (\%) & 96 (96.97) \\
\hline
\end{tabular}

Table 2. Analysis according to gender

\begin{tabular}{|c|c|c|c|c|c|}
\hline \multicolumn{6}{|c|}{ Summary of the Number of Censored and Uncensored Values } \\
\hline Stratum & Sex & Total & Event & Censored & $\begin{array}{l}\text { Percent } \\
\text { Censored }\end{array}$ \\
\hline 1 & $\mathrm{~F}$ & 34 & 2 & 32 & 94.12 \\
\hline 2 & M & 65 & 20 & 45 & 69.23 \\
\hline Total & & 99 & 22 & 77 & 77.78 \\
\hline \multicolumn{6}{|c|}{ Test of Equality over Strata } \\
\hline Test & Chi- & uare & DF & \multicolumn{2}{|c|}{ Pr > Chi-Square } \\
\hline Log-Rank & & & 1 & \multicolumn{2}{|c|}{0.0094} \\
\hline Wilcoxon & & & 1 & \multicolumn{2}{|c|}{0.0141} \\
\hline$-2 \log (\mathrm{LR})$ & \multicolumn{2}{|c|}{9.0791} & 1 & \multicolumn{2}{|c|}{0.0026} \\
\hline
\end{tabular}

Standard Deviation (range), ie. Mean $\pm \mathrm{SD}=$ Standard Deviation (range) or median (range) for continuous variables, and absolute frequency (relative frequency) for categorical variables.

We started the analysis for general factors that may influence indirectly the free of disease survival period based on sex.

There were differences between the KaplanMeier curves for free of disease survival between women and men, the prognosis being more severly for men (see Chart 1 and Table 2).

The type of surgical approach used was dictated by the localization of the tumor according to international site-specific resection recommendations.

With a lot of patients without metastasis, without peritoneal carcinomatosis, there were no surgical gestures associated with colectomy

Chart 1.

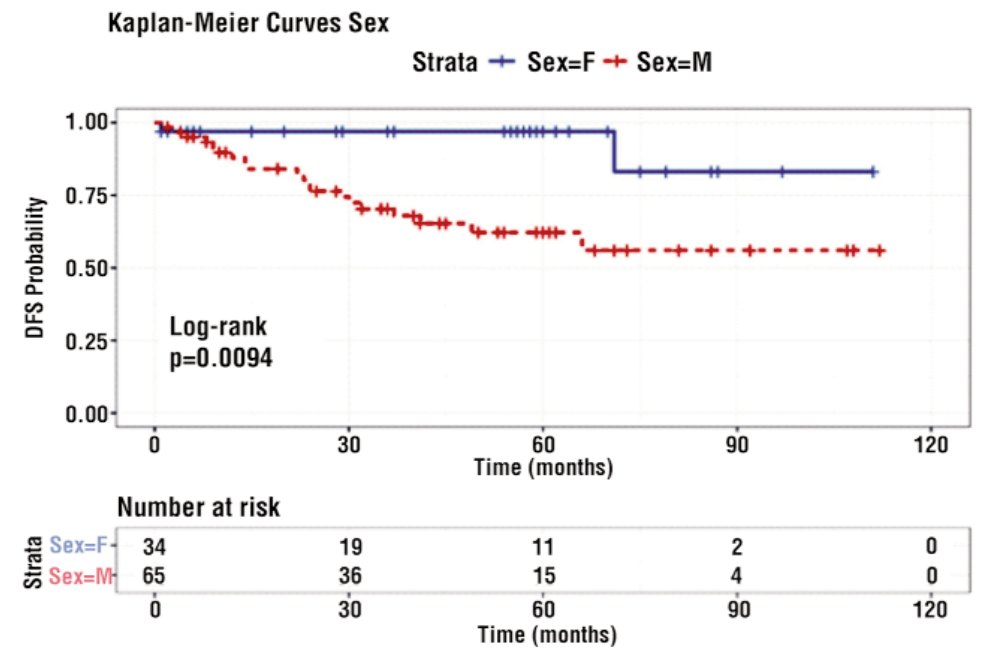


as would be required in some patients, ie. with synchronous liver metastases that would require an extra liver intervention.

Depending on the location of the tumor and the types of operations performed, tumors located on the right colon, tumors located on the left colon, and a third category with multiple localizations (left and right colon) were differentiated (see Chart 2 and Table 3).

There were no differences between free of disease survival curves.

Analyzing the number of recurrences according to tumor (T) with $\mathrm{N}_{0}$ and $\mathrm{M} 0$, we highlighted the following statistical distribution (Chart 3 and Table 4).

Following the analysis of histopathological results and prognosis factors, including
Table 3. Prognostic analysis considering the location of tumours on the colon

\begin{tabular}{|c|c|c|c|c|c|}
\hline \multicolumn{6}{|c|}{ Summary of the Number of Censored and Uncensored Values } \\
\hline Stratum & Location & Total & Event & Censored & $\begin{array}{l}\text { Percent } \\
\text { Censored }\end{array}$ \\
\hline 1 & RIGHT & 43 & 7 & 36 & 83.72 \\
\hline 2 & LEFT & 45 & 14 & 31 & 68.89 \\
\hline 3 & BOTH & 11 & 1 & 10 & 90.91 \\
\hline Total & & 99 & 22 & 77 & 77.78 \\
\hline \multicolumn{6}{|c|}{ Test of Equality over Strata } \\
\hline Test & \multicolumn{2}{|c|}{ Chi-Square } & DF & \multicolumn{2}{|c|}{ Pr >Chi-Square } \\
\hline Log-Rank & \multicolumn{2}{|c|}{2.6944} & 2 & \multicolumn{2}{|c|}{0.2600} \\
\hline Wilcoxon & \multicolumn{2}{|c|}{1.8594} & 2 & \multicolumn{2}{|c|}{0.3947} \\
\hline$-2 \log (\mathrm{LR})$ & \multicolumn{2}{|c|}{3.0783} & 2 & \multicolumn{2}{|c|}{0.2146} \\
\hline
\end{tabular}

tumoral biomarkers, patients were divided into 2 groups: one in which patients received

Chart 2.

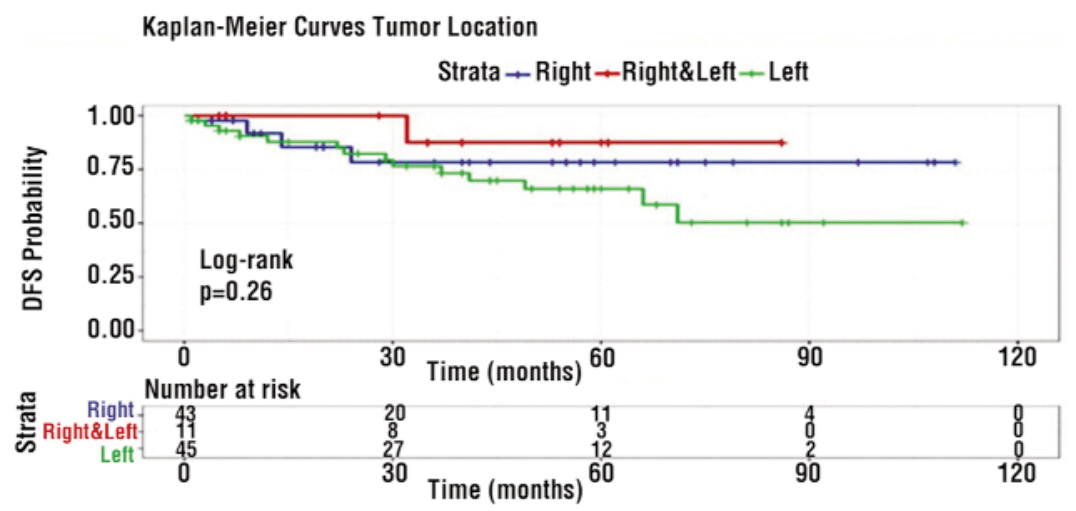

Kaplan-Meier Curves Tumoral Stage T

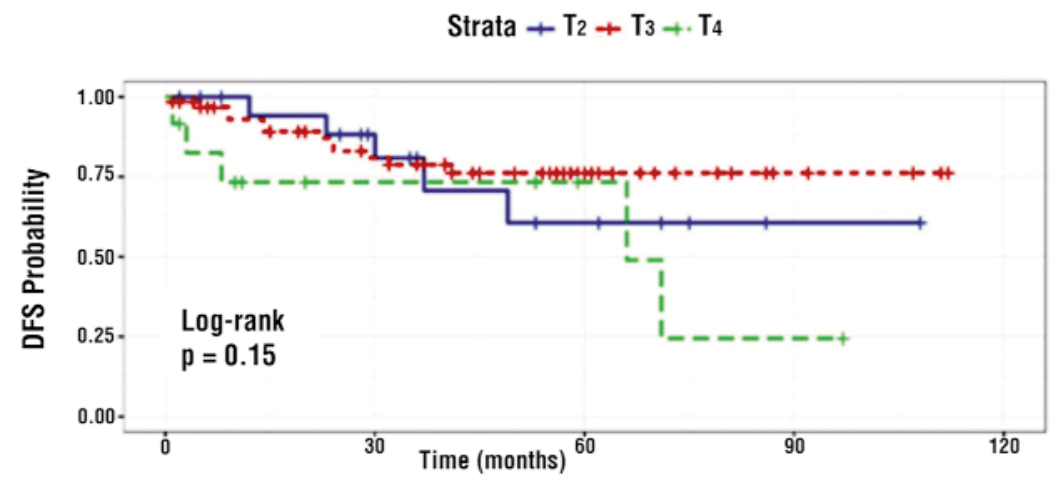

Chart 3.

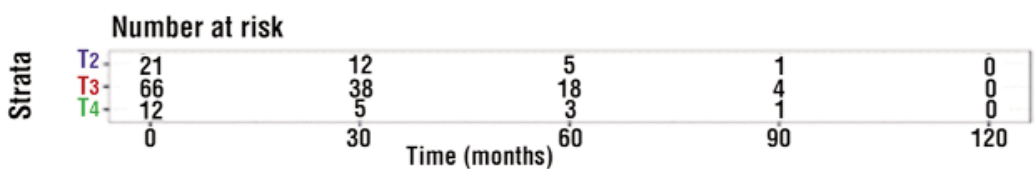


Table 4. Prognostic analysis considering factor $T$

\begin{tabular}{lccccc}
\hline \multicolumn{5}{c}{ Summary of the Number of Censored and Uncensored Values } \\
\hline Stratum & $\begin{array}{c}\text { T Stage } \\
\text { Censored }\end{array}$ & Total & Failed & Censored & Percent \\
\hline 1 & T2 & 21 & 5 & 16 & 76.19 \\
\hline 2 & T3 & 66 & 12 & 54 & 81.82 \\
\hline 3 & T4 & 12 & 5 & 7 & 58.33 \\
\hline Total & & 99 & 22 & 77 & 77.78 \\
\hline
\end{tabular}

\begin{tabular}{lccc}
\hline \multicolumn{4}{c}{ Test of Equality over Strata } \\
\hline Test & Chi-Square & DF & Pr $>$ Chi-Square \\
\hline Log-Rank & 3.8480 & 2 & 0.1460 \\
\hline Wilcoxon & 2.7872 & 2 & 0.2482 \\
\hdashline-2 Log(LR) & 3.0361 & 2 & 0.2191 \\
\hline
\end{tabular}

chemotherapy (patients with a higher risk for recurrence) and patients without chemotherapy (with a low risk for recurrence).

Comparing disease free survival between the 2 groups, we determined the following recurrence percentages (see Chart 4 and Table 5).

We found no differences between the survival curves for the 2 groups, noting that this study is observational, not controlled-trial, chemotherapy administration being made in a non-randomized way based on decision made by the multidisciplinary oncological meetings for each individual patient.

Known risk factors which suggested post-op usage of different chemotherapy protocols were analyzed separately in our study.

The first analyzed risk factor is represented
Table 5. Prognostic analysis considering the presence or absence of adjuvant chemotherapy

\begin{tabular}{|c|c|c|c|c|c|}
\hline \multicolumn{6}{|c|}{ Summary of the Number of Censored and Uncensored Values } \\
\hline Stratum & Chemotherapy & Total & Event & Censored & $\begin{array}{l}\text { Percent } \\
\text { Censored }\end{array}$ \\
\hline 1 & Yes & 22 & 6 & 16 & 72.73 \\
\hline 2 & No & 77 & 16 & 61 & 79.22 \\
\hline Total & & 99 & 22 & 77 & 77.78 \\
\hline \multicolumn{6}{|c|}{ Test of Equality over Strata } \\
\hline Test & Chi-Squar & & DF & $\operatorname{Pr}>1$ & Chi-Square \\
\hline Log-Rank & 0.4882 & & 1 & & .4847 \\
\hline Wilcoxon & 1.6484 & & 1 & & .1992 \\
\hline$-2 \log (\mathrm{LR})$ & 0.5151 & & 1 & & .4729 \\
\hline
\end{tabular}

by the carcinoembryonic antigen (CEA). In the studied sample, we observed that this marker was dosed pre-operatively, and only 5 patients had a positive result, for that reason, no significant conclusion could be made.

Continuing with the risk factor analysis for colon cancer, we studied the presence or absence of vascular emboli among the patients from our study and statistical correlations were made regarding the recurrence risk based on two groups: one with and one without vascular emboli (see Chart 5 and Table 6).

There were no differences between the survival curves in our study.

Another studied criterion regarding recurrence risk was the classification based on tumor grading (see Chart 6 and Table 7).

Kaplan-Meier Curves Adjuvant Chemotherapy

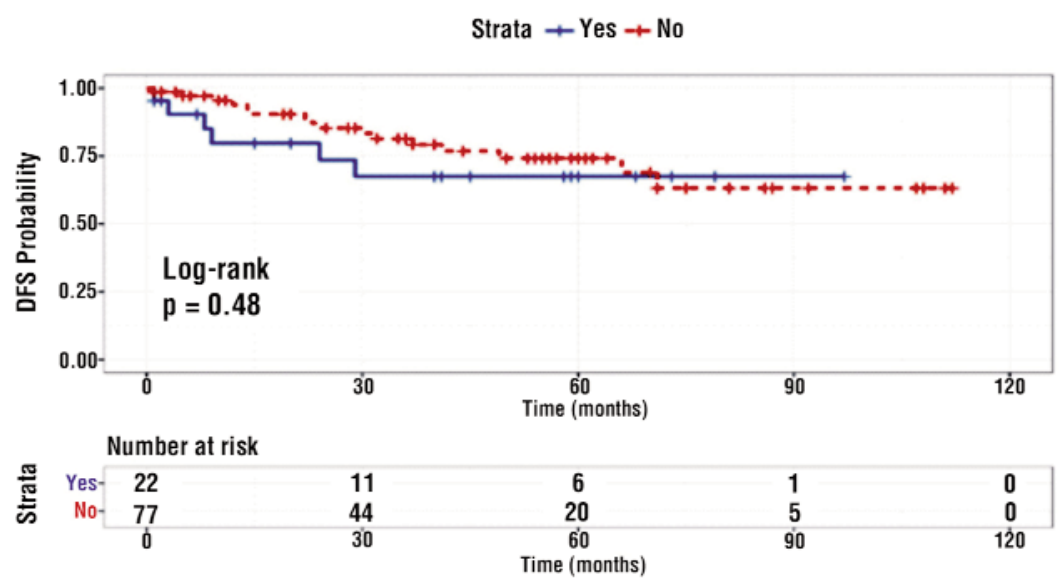


Chart 5.

Kaplan-Meier Curves Vascular Emboli

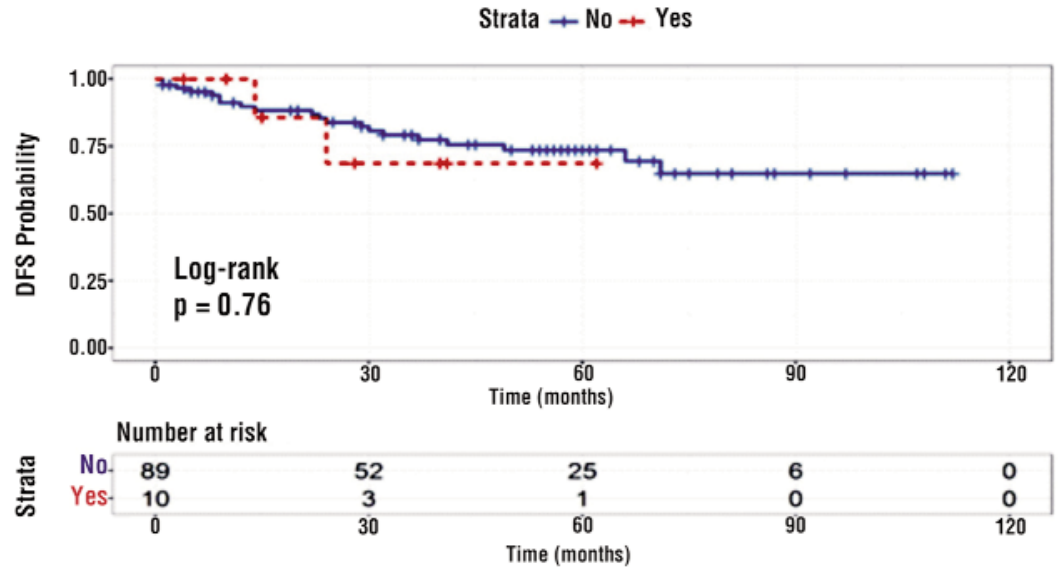

Table 6. Prognostic analysis considering the presence or absence of vascular emboli

\begin{tabular}{lccccc}
\hline \multicolumn{5}{c}{ Summary of the Number of Censored and Uncensored Values } \\
\hline Stratum & Vasc. Emboli & Total & Event & Censored & $\begin{array}{c}\text { Percent } \\
\text { Censored }\end{array}$ \\
\hline 1 & Yes & 10 & 2 & 8 & 80.00 \\
\hline 2 & No & 89 & 20 & 69 & 77.53 \\
\hline Total & & 99 & 22 & 77 & 77.78 \\
\hline
\end{tabular}

\section{Test of Equality over Strata}

\begin{tabular}{lccc}
\hline Test & Chi-Square & DF & Pr $>$ Chi-Square \\
\hline Log-Rank & 0.0939 & 1 & 0.7593 \\
\hline Wilcoxon & 0.0319 & 1 & 0.8583 \\
\hline -2Log(LR) & 0.2546 & 1 & 0.6139 \\
\hline
\end{tabular}

Table 7. Prognostic analysis considering tumour grading

\begin{tabular}{|c|c|c|c|c|c|}
\hline \multicolumn{6}{|c|}{ Summary of the Number of Censored and Uncensored Values } \\
\hline Stratum & Grading & Total & Event & Censored & $\begin{array}{l}\text { Percent } \\
\text { Censored }\end{array}$ \\
\hline 1 & G1 & 44 & 10 & 34 & 77.27 \\
\hline 2 & G2 & 23 & 5 & 18 & 78.26 \\
\hline 3 & G3 & 32 & 7 & 25 & 78.13 \\
\hline Total & & 99 & 22 & 77 & 77.78 \\
\hline \multicolumn{6}{|c|}{ Test of Equality over Strata } \\
\hline Test & \multicolumn{2}{|c|}{ Chi-Square } & DF & \multicolumn{2}{|c|}{$\mathrm{Pr}>$ Chi-Square } \\
\hline Log-Rank & \multicolumn{2}{|c|}{0.0605} & 2 & \multicolumn{2}{|r|}{0.9702} \\
\hline Wilcoxon & \multicolumn{2}{|c|}{0.3127} & 2 & \multicolumn{2}{|r|}{0.8553} \\
\hline$-2 \log (\mathrm{LR})$ & \multicolumn{2}{|c|}{0.0431} & 2 & \multicolumn{2}{|r|}{0.9787} \\
\hline
\end{tabular}

Chart 6.

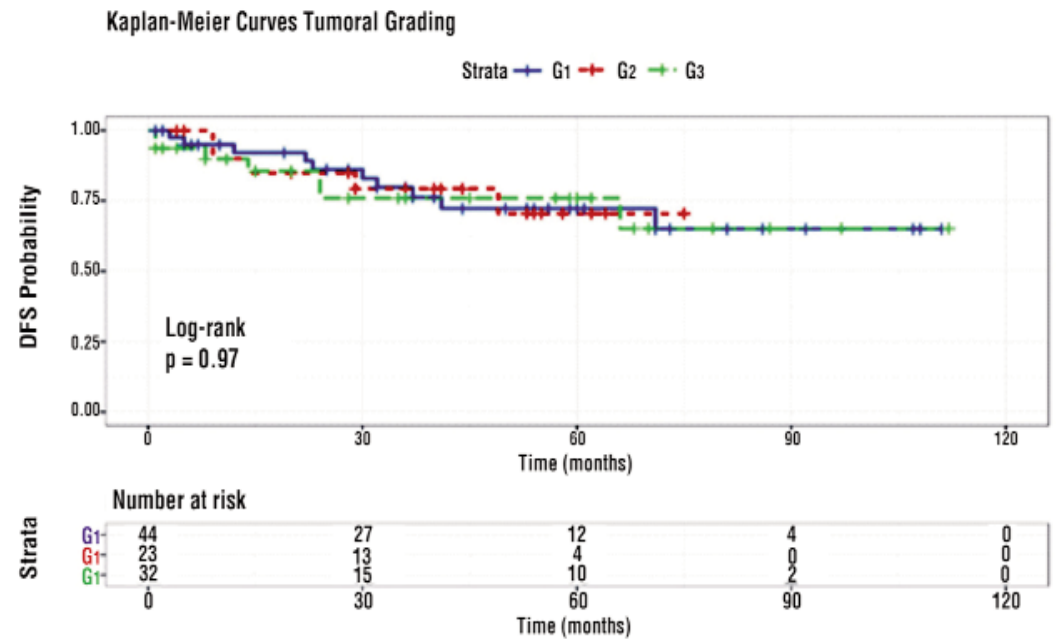


In this study, mucus-secreting adenocarcinoma is considered as G3 (anaplastic/nondifferentiated) and we specify that the classification of mucinous ADK (adenocarcinoma) was not made based on the presence of d'MMR (deficient mismatch repair) or p'MMR (proficient mismatch repair).

There were no differences between the survival curves for the 3 tumor grades.

Regarding intestinal occlusion by tumor at the time of diagnosis, the statistical analysis is depicted in Chart 7 and Table 8.

There were no differences between the survival curves in our study.

Regarding the presence of intestinal perforation at the time of diagnosis, the analysis of recurrence rates is highlighted in Chart 8 and Table 9.

As one can see in Table 9, the p value at the Wilcoxon test is not significant; the visual analysis of the survival chart suggests that the difference between the survival curves of the 2 strata is maximum at 30 months postop, after 60 months the 2 curves getting very close to each other.

Regarding utilization of molecular biomarkers, we found 27 cases for which molecular biomarkers were tested, for 26 patients a MMR and MSI profile was tested while for 1 patient Kirsten Ras (KRAS) status was tested, for the other 72 patients from our lot, no molecular biomarkers were tested.

Among the 26 patients for which MMR and MSI tests were performed, we calculated a risk for recurrence according to the presence of
Table 8. Prognostic analysis considering the presence or absence of occlusion at the time of the operation

\begin{tabular}{lccccc}
\hline \multicolumn{5}{c}{ Summary of the Number of Censored and Uncensored Values } \\
\hline Stratum & Ocluzie & Total & Events & Censored & $\begin{array}{c}\text { Percent } \\
\text { Censored }\end{array}$ \\
\hline 1 & No & 83 & 19 & 64 & 77.11 \\
\hline 2 & Yes & 16 & 3 & 13 & 81.25 \\
\hline Total & & 99 & 22 & 77 & 77.78 \\
\hline
\end{tabular}

\begin{tabular}{lccc}
\hline \multicolumn{4}{c}{ Test of Equality over Strata } \\
\hline Test & Chi-Square & DF & Pr $>$ Chi-Square \\
\hline Log-Rank & 0.0000 & 1 & 0.9966 \\
\hline Wilcoxon & 0.0397 & 1 & 0.8420 \\
\hline-2 Log(LR) & 0.0159 & 1 & 0.8997 \\
\hline
\end{tabular}

d'MMR or p'MMR and MSI vs MSS (microsatelite stable) (see Table 10 and Chart 9).

The graphic analysis highlights that as we get far from the time of surgery, the survival curve corresponding to p'MMR approaches the horizontal axis, while the corresponding curve for d'MMR remains at a constant distance from the horizontal axis. For all 3 tests the $p$ value is borderline significant.

\section{Univariate and Multivariate Cox Regression in Patients with Colon Cancer}

Cox univariate regression (the parameters being the ones that the tests for the survival curves for the different strata had low $p$ values [were considered eligible parameters for which at least one $p$ value was below

Chart 7.

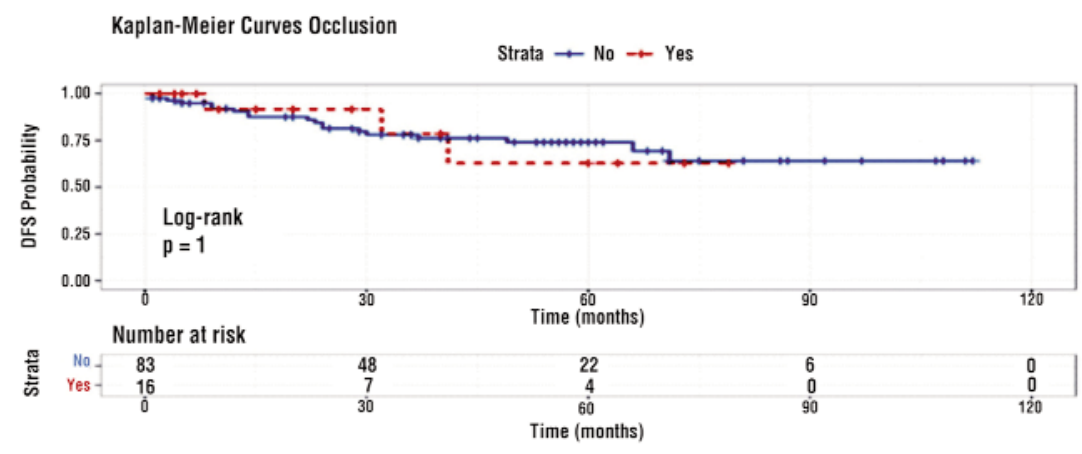


Chart 8.

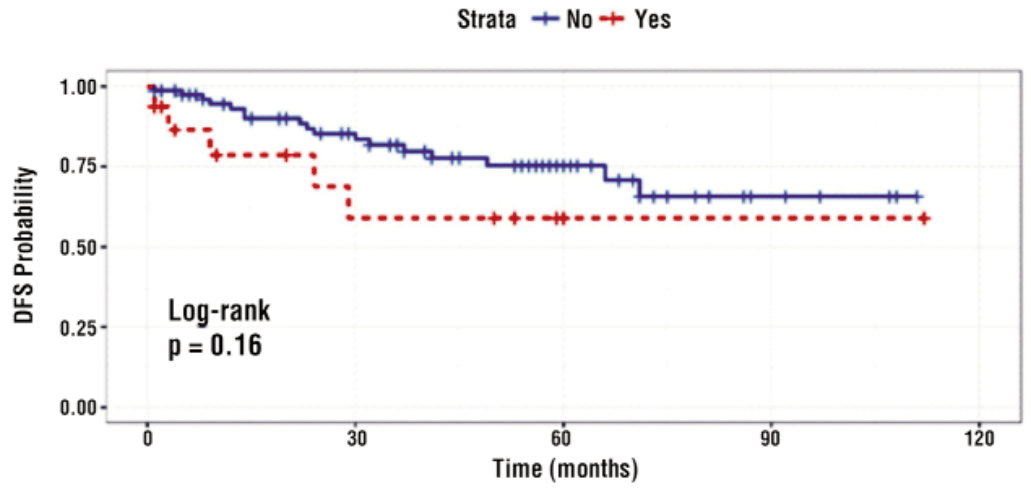

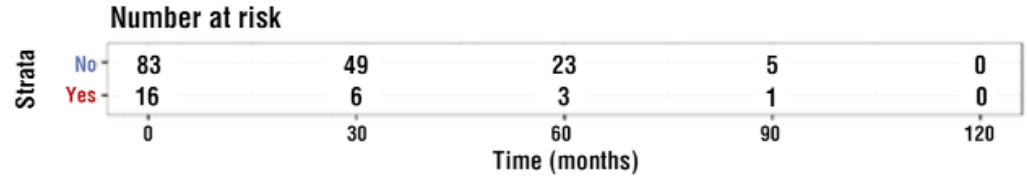

Table 9. Prognostic analysis considering the presence or absence of perforation

\begin{tabular}{cccccc}
\hline \multicolumn{5}{c}{ Summary of the Number of Censored and Uncensored Values } \\
\hline Stratum & Perforation & Total & Event & Censored & $\begin{array}{c}\text { Percent } \\
\text { Censored }\end{array}$ \\
\hline 1 & No & 83 & 17 & 66 & 79.52 \\
\hdashline 2 & Yes & 16 & 5 & 11 & 68.75 \\
\hline Total & & 99 & 22 & 77 & 77.78 \\
\hline
\end{tabular}

\begin{tabular}{lccc}
\hline \multicolumn{4}{c}{ Test of Equality over Strata } \\
\hline Test & Chi-Square & DF & Pr > Chi-Square \\
\hline Log-Rank & 2.0089 & 1 & 0.1564 \\
\hline Wilcoxon & 3.3328 & 1 & 0.0679 \\
\hline-2 Log $($ LR $)$ & 1.5677 & 1 & 0.2105 \\
\hline
\end{tabular}

Table 10. Prognostic analysis considering the MMR status

Summary of the Number of Censored and Uncensored Values

\begin{tabular}{lccccc}
\hline Stratum & MMR & Total & Failed & Censored & $\begin{array}{c}\text { Percent } \\
\text { Censored }\end{array}$ \\
\hline 1 & d'MMR & 11 & 1 & 10 & 90.91 \\
\hline 2 & p'MMR & 15 & 7 & 8 & 53.33 \\
\hline Total & & 26 & 8 & 18 & 69.23 \\
\hline
\end{tabular}

\begin{tabular}{lccc}
\hline \multicolumn{4}{c}{ Test of Equality over Strata } \\
\hline Test & Chi-Square & DF & Pr >Chi-Square \\
\hline Log-Rank & 2.8642 & 1 & 0.0906 \\
\hline Wilcoxon & 2.0287 & 1 & 0.1543 \\
\hline-2 Log(LR) & 3.1122 & 1 & 0.0777 \\
\hline
\end{tabular}

Kaplan-Meier Curves MMR Status

Strata $+\mathrm{d} M M R+\mathrm{p} M M R$

Chart 9

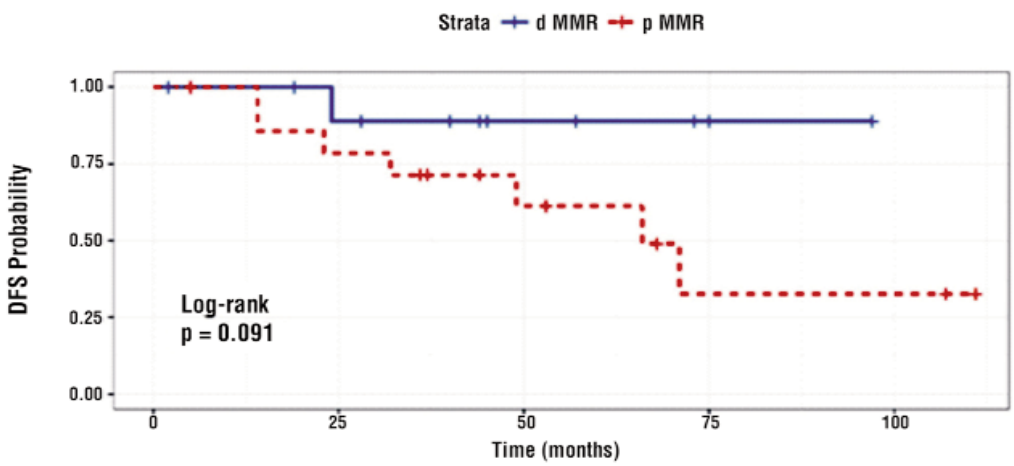

Number at risk

\begin{tabular}{|c|c|c|c|c|c|}
\hline$\underset{\mathbb{2}}{\mathbb{2}} \mathrm{d} M M R$ - & 11 & 8 & 4 & 2 & 0 \\
\hline p MMR - & 15 & 11 & 6 & 2 & 2 \\
\hline & 0 & 25 & $\begin{array}{l}50 \\
\text { ime }\end{array}$ & 75 & 100 \\
\hline
\end{tabular}


Table 11. Analysis of Maximum Likelihood Estimates

\begin{tabular}{|c|c|c|c|c|c|c|c|c|c|}
\hline \multirow{2}{*}{$\begin{array}{l}\text { Parameter } \\
\text { Sex }\end{array}$} & \multirow[b]{2}{*}{$\mathrm{M}^{\prime} \mathrm{H}$} & \multirow{2}{*}{$\begin{array}{c}\text { DF } \\
1\end{array}$} & \multirow{2}{*}{$\begin{array}{c}\begin{array}{c}\text { Parameter } \\
\text { Estimate }\end{array} \\
1.71102 \\
\end{array}$} & \multirow{2}{*}{$\begin{array}{c}\begin{array}{c}\text { Standard } \\
\text { Error }\end{array} \\
0.74292\end{array}$} & \multirow{2}{*}{$\begin{array}{c}\text { Chi-Square } \\
5.3043\end{array}$} & \multirow{2}{*}{$\begin{array}{l}\text { p Value } \\
0.0213\end{array}$} & \multirow{2}{*}{$\begin{array}{c}\begin{array}{c}\text { Hazard } \\
\text { Ratio }\end{array} \\
5.535\end{array}$} & \multicolumn{2}{|c|}{ Cl $95 \%$ for HR } \\
\hline & & & & & & & & 1.290 & 23.739 \\
\hline Perforation & $1^{\prime} \mathrm{H}$ & 1 & 0.70801 & 0.51125 & 1.9178 & 0.1661 & 2.030 & 0.745 & 5.529 \\
\hline T Stage & $\mathrm{T}^{\prime} \mathrm{H}$ & 1 & 0.94296 & 0.51119 & 3.4027 & 0.0651 & 2.568 & 0.943 & 6.993 \\
\hline MMR & d'MMR'H & 1 & -1.62124 & 1.07083 & 2.2922 & 0.1300 & 0.198 & 0.024 & 1.612 \\
\hline
\end{tabular}

H Sex M vs F; Perforation 1 = Yes vs No Perforation; T4 vs T3 \& T2; d'MMR vs p'MMR

0.10)] is shown in Table 11.

For the cox regression, a modification was made in the manner in which tumoral $\mathrm{T}$ stage was quantified, because the majority of studies revealed that $\mathrm{T}_{4}$ tumors have a high disease relapse risk compared to other tumors (for $\mathrm{T}_{2}$ and $\mathrm{T}_{3}$ tumors it is considered that the risk is similar). In a first step we performed a Cox univariate regression to see how each parameter independently influences disease relapse.

In the Cox univariate regression we observed that male sex has, compared to female sex, a risk for relapse 5.5 times higher and this effect has a statistical significance $(\mathrm{HR}=5.53, \mathrm{p}<0.05, \mathrm{IC} 95 \%=1.29$ to 23.73$)$.

Also, for $\mathrm{T}_{4}$ tumors the relapse risk is 2,5 times greater compared to $\mathrm{T}_{2}$ and $\mathrm{T}_{3}$ tumors, but the effect is not significant ( $\mathrm{HR}=2.56$, $\mathrm{p}=0.06, \mathrm{IC} 95 \%=0.94$ to 6.99 ).

For patients with intestinal perforation at the time of surgery, we observed a relatively important risk for disease relapse (2 times greater than for patients without perforation), but the effect does not have statistical significance $(\mathrm{p}>0.05)$.

The analysis of MMR influence was made on 26 patients, but the small value of HR (0.20) for d'MMR was noticed, which suggest a risk for relapse 5 times smaller than for p'MMR, also IC95\% is asymmetrical reported to 1 ( $\mathrm{HR}=1$ meanse no risk differences).
Although the $\mathrm{p}$ value has no statistical significance $(p>0.05)$, we decided that for the multivariate model MMR should be introduced, along with $\mathrm{T}$ factor and sex (introduced because for them the $p$ value was $<0.10$ ).

The multivariate model is slightly oversaturated (an empirical rule tells us that for each independent variable we introduce in the model, we need 10 observations; in our case we have only 26 ).

The multivariate Cox regression: (Table 12).

In the first model of multivariate analysis, no predictor has statistical significance, a fact that may be explained by the small size of the sample.

Meanwhile, we observe a modification of the HR value, which decreases for $\mathrm{T}_{4}$ tumors and sex and increases for MMR, suggesting a possible interaction between the 3 predictors, but the size of the sample does not allow to introduce terms for predictor interaction in the model.

By eliminating the $\mathrm{T}$ parameter from the model we acquire a 2 predictor model (Table 13).

No predictor has statistical significance (with the univariate model, male gender was associated with a relapse risk 5.5 times greater than female). There might be an interaction between the predictors, but if we try introducing a term of interaction between

Table 12. Analysis of Maximum Likelihood Estimates

\begin{tabular}{|c|c|c|c|c|c|c|c|c|c|}
\hline \multirow{2}{*}{$\begin{array}{l}\text { Parameter } \\
\text { Sex }\end{array}$} & \multirow[b]{2}{*}{$M$} & \multirow{2}{*}{$\begin{array}{c}\text { DF } \\
1\end{array}$} & \multirow{2}{*}{$\begin{array}{c}\begin{array}{c}\text { Parameter } \\
\text { Estimate }\end{array} \\
1.6261\end{array}$} & \multirow{2}{*}{$\begin{array}{c}\begin{array}{c}\text { Standard } \\
\text { Error }\end{array} \\
1.1729\end{array}$} & \multirow{2}{*}{$\begin{array}{c}\text { Chi-Square } \\
5.3043\end{array}$} & \multirow{2}{*}{$\begin{array}{c}\text { p Value } \\
0.166\end{array}$} & \multirow{2}{*}{$\begin{array}{c}\begin{array}{c}\text { Hazard } \\
\text { Ratio }\end{array} \\
5.083\end{array}$} & \multicolumn{2}{|c|}{ CI $95 \%$ for HR } \\
\hline & & & & & & & & 0.5102 & 50.648 \\
\hline T Stage & T4 & 1 & 0.6253 & 0.8875 & 3.4027 & 0.481 & 1.868 & 0.3281 & 10.642 \\
\hline MMR & d'MMR & 1 & -1.4067 & 1.0893 & 2.2922 & 0.197 & 0.244 & 0.0289 & 2.071 \\
\hline
\end{tabular}


Table 13. Analysis of Maximum Likelihood Estimates

\begin{tabular}{|c|c|c|c|c|c|c|c|c|c|}
\hline Parameter & & DF & $\begin{array}{l}\text { Parameter } \\
\text { Estimate }\end{array}$ & $\begin{array}{c}\text { Standard } \\
\text { Error }\end{array}$ & Chi-Square & p Value & $\begin{array}{c}\text { Hazard } \\
\text { Ratio }\end{array}$ & Cl 95 & or HR \\
\hline Sex & $M$ & 1 & 1.4017 & 1.1060 & 5.3043 & 0.205 & 4.062 & 0.4648 & 35.496 \\
\hline MMR & d MMR & 1 & -1.4892 & 1.0773 & 2.2922 & 0.167 & 0.225 & 0.0273 & 1.863 \\
\hline
\end{tabular}

gender and MMR in this model, it becomes divergent, and the coefficients of the independent variables couldn't be estimated.

A descriptive analysis reveals that the percentage of women with the d'MMR phenotype is greater than in men (Table 14).

Beside age, differences of phenotype seem to play a role in the more favorable prognosis in women, but we cannot draw the conclusion that d'MMR phenotype is more often encountered in women, having considered that the studied sample is small at data comes from a retrospective observational study.

\section{Discussion}

Looking at the analysis for general factors that can modify the rate of survival, statistical correlations based on gender in the studied sample, highlight significantly better rates of survival for female subjects.

Regarding the types of surgical procedures, a relatively homogenous distribution appears between right or left side tumour localization and a 4 times lower distribution for multiple localisation, in the studied sample no significant differences being found between the disease free survival curves as compared to other studies that shows a higher recurrence risk for right colon tumors (21).

In the case of stage I and II colon cancer, we determined a risk of tumour recurrence similar to other studies $(14,19)$.

Table 14. MMR distribution on gender

\begin{tabular}{lr}
\hline Sex & \\
\hline Females & $4(50)$ \\
d'MMR $-\mathrm{Nr}(\%)$ & $4(50)$ \\
p'MMR - Nr (\%) & \\
\hline Males & $7(38.89)$ \\
\hline d'MMR - Nr (\%) & $11(61.11)$ \\
\hline
\end{tabular}

The analysis of the survival curve for $\mathrm{T}$ criterion with $\mathrm{N}_{0}$ and $\mathrm{M}_{0}$ reveals that although we see a poorer prognosis for $\mathrm{T}_{4}$ patients compared to $\mathrm{T}_{2}$ and $\mathrm{T}_{3}$, the differences have no statistical significance.

This fact may suggest extending the notion of relapse risk for $\mathrm{T}_{2}$ tumors similar to those in stage II ( $\mathrm{T}_{3}$ and $\mathrm{T}_{4}$ with high risk), for which adjuvant chemotherapy is necessary $(4,22)$.

Analysing patients on the basis of post-op chemotherapy administration (according to risk factors), the 2 survival curves have no significant differences.

This being a retrospective study and chemotherapy administration being made in a non-randomized fashion, we cannot asses with certainty the benefit of chemotherapy.

In the literature there is still debate surrounding the usefulness of chemotherapy for this patients $(3,4,6,8,10,15,20)$.

Although we could not have statistically significant conclusions regarding a positive pre-op CEA test due to the small number of patients, but CEA is still a debatable criterion for including these patients in a high-risk group (7).

The presence of vascular emboli, considered a general risk factor for recurrence $(7,13)$ has not been observed to cause any modifications in the survival curves for the 2 groups in our study (with or without vascular emboli).

Tumour grading analysis suggests that there is no differences between survival curves for the 3 tumoural grades, which is divergent to other similar studies $(23,24)$.

Intestinal occlusion at the time of diagnosis does not highlight different survival curves compared to patients with scheduled surgery, literature showing divergent opinions in this matter $(4,8)$.

Intestinal perforation at the time of diagnosis is not a significant risk factor for relapse, 
as our study shows, against to other studies in the literature $(6,25-28)$.

The risk of relapse is 2 times greater for patients with perforation compared to nonperforated cases, and is higher in the first 30 months post-op, eventually the survival curves getting close to each other, being almost similar at 60 months post-op.

The use of molecular biomarkers brings extra value for patients considered to be at high risk for relapse $(29,19)$.

In our study there were 26 patients who had a post-op analysis of the MSI and MMR status. The survival curve for p'MMR gets very close to the horizontal axis starting on the $25^{\text {th }}$ month post-op, as opposed to d'MMR which remains at a relatively constant distance to the horizontal axis, this may suggest that the d'MMR, MSI status, has a better prognosis for longer periods which is confirmed by other studies.

In this study we observed that the d MMR phenotype was associated with a better prognosis regarding disease free survival, relapse risk being 5 times smaller in patient with d MMR phenotype and the effect has no statistical significance $(p>0.05)$. Our results are compatible with studies on much larger samples (18).

The utilization of biomarkers for stages I and II colon cancer, regarding the risk for recurrence represents a good prognosis factor suggesting whether adjuvant chemotherapy is necessary $(3,4,18,19,29)$.

\section{Conclusions}

The systematic use of MMR-MSI status for all patients with colorectal cancer with $\mathrm{T}_{2}, \mathrm{~T}_{3}, \mathrm{~T}_{4}$ tumours, negative nodes and no metastases represents an efficient method to determine the relapse risk and consequently being beneficial in the assessment of the need for adjuvant chemotherapy for patients with a high-risk of relapse.

The global analysis for colon cancer stages I and II with high recurrence risk suggests that the systematic and combined use of histopathological risk factors and molecular biomarkers should be introduced in practice despite the still high costs of these tests.

In our study males appear to be associated with a higher risk of recurrence.

\section{Acknowledgements}

We thank Mr. Dan Constantin Popescu for the assistance given in the statistical processing of the data.

\section{Conflict of Interest}

The authors declare no conflicts of interest.

\section{Authors' Contributions}

Authors make substantial contributions to conception and design, acquisition of data, analysis and interpretation of data.

\section{Refferences}

1. Ferlay J, Soerjomataram I, Dikshit R, Eser S, Mathers C, Rebelo M, et al. Cancer incidence and mortality worldwide: sources, methods and major patterns in GLOBOCAN 2012. Int J Cancer. 2015; 136(5): E359-86.

2. Lecomte T, edtors. Thesaurus National de Cancerologie Digestive, Chap. 3: Cancer du côlon non métastatique (mise à jour le 18/04/2018).

3. André T, de Gramont A, Vernerey D, Chibaudel B, Bonnetain F, TijerasRaballand $A$, et al. Adjuvant fluorouracil, leucovorin, and oxaliplatin in stage II to III colon cancer: updated 10-year survival and outcomes according to BRAF mutation and mismatch repair status of the MOSAIC study. J Clin Oncol. 2015; 33(35):4176-87.

4. Märkl B, Märkl M, Schaller T, Mayr P, Schenkirsch G, Kriening B, et al. A new simple morphology-based risk score is prognostic in stage $1 / / I$ colon cancers. Cancer Med. 2016;5(7):1492-501.

5. Zhang CD, Wang JN, Sui BQ, Zeng YJ, Chen JQ, Dai DQ. Prognostic and predictive model for stage II colon cancer patients with nonemergent surgery: who should receive adjuvant chemotherapy? Medicine (Baltimore). 2016:95(1):e2190.

6. Meyers BM, Cosby R, Quereshy F, Jonker D. Adjuvant systemic chemotherapy for stages II and III colon cancer after complete resection: a clinical practice guideline. Curr Oncol. 2016; 23(6):418-424.

7. Amri R, England J, Bordeianou LG, Berger DL. Risk stratification in patients with stage II colon cancer. Ann Surg Oncol. 2016; 23(12): 3907-3914. Epub 2016 Jul 5

8. Hu JM, Chou YC, Wu CC, Hsiao CW, Lee CC, Chen CT, et . Adjuvant chemotherapy with tegafur/uracil for more than 1 year improves disease-free survival for low-risk Stage II colon cancer. J Chin Med Assoc. 2016;79(9):477-88.

9. Lonardi S, Sobrero A, Rosati G, Di Bartolomeo M, Ronzoni M, Aprile $G$, et al. Phase III trial comparing 3-6 months of adjuvant FOLFOX4/XELOX in stage II-III colon cancer: safety and compliance in the TOSCA trial. Ann Oncol. 2016:27(11):2074-2081.

10. Manjelievskaia J, Brown D, McGlynn KA, Anderson W, Shriver CD, 
Zhu K. Chemotherapy use and survival among young and middle-aged patients with colon cancer. JAMA Surg. 2017;152(5): 452-459.

11. Mejri N, Dridi M, Labidi S, El Benna H, Daoud N, Boussen H. Annual hazard rate of relapse of stage II and IIIcolorectal cancer after primary therapy. Clin Transl Oncol. 2017;19(12):1524-1530.

12. Mondaca S, Villalón C, Leal JL, Zúñiga Á, Bellolio F, Padilla O, et al. Benefit of adjuvant 5 -fluorouracil based chemotherapy for colon cancer: a retrospective cohort study. Rev Med Chil. 2016;144(2): 145-51. Spanish

13. Cienfuegos JA, Martínez P, Baixauli J, Beorlegui C, Rosenstone S, Sola JJ, et al. Perineural invasion is a major prognostic and predictive factor of response to adjuvant chemotherapy in stage I-II colon cancer. Ann Surg Oncol. 2017;24(4):1077-84.

14. Daly MC, Hanseman D, Abbott DE, Shah SA, Paquette IM. Hospital variability in use of adjuvant chemotherapy for patients with stage 2 and 3 colon cancer. Dis Colon Rectum. 2016; 59(12):1134-41.

15. Ha GS, Kim YW, Choi EH, Kim IY. Factors Associated with the lack of adjuvant chemotherapy following curative surgery for stage II and III colon cancer: a korean national cohort study. Anticancer Res. 2017;37(2):915-922.

16. McCleary NJ, Benson AB, Dienstmann R, Personalizing adjuvant therapy for stage II/III colorectal cancer. Am Soc Clin Oncol Educ Book. 2017;37:232-245.

17. Park JS, Chon HJ, Jeung HC, Shin SJ, Rha SY, Ahn JB, et al. High-risk clinicopathological features and their predictive significance in Korean patients with stage II colon cancer. J Cancer Res Clin Oncol. 2016;142(9):2051-9.

18. Tougeron D, Mouillet G, Trouilloud I, Lecomte T, Coriat R, Aparicio T. Efficacy of adjuvant chemotherapy in colon cancer with microsatellite instability: a large multicenter AGEO study. J Natl Cancer Inst. 2016;108(7).

19. Vogelaar F, Van Erning F, Reimers M, Van Der Linden J, Pruijt J, Van Den Brule A, et al. The prognostic value of Microsatellite Instability, KRAS, BRAF and PIK3CA mutations in stage II colon cancer patients. Mol Med. 2015:1-26.

20. Shah MA, Renfro LA, Allegra CJ, André T, de Gramont A, Schmoll
HJ, et al. Impact of patient factors on recurrence risk and time dependency of Oxaliplatin benefit in patients with colon cancer: Analysis From Modern-Era Adjuvant Studies in the Adjuvant Colon Cancer End Points (ACCENT) Database. J Clin Oncol. 2016;34(8): 843-53.

21. Moldovanu R, Dimofte G, Stefan I, Filip V, Vlad N, Curcă G, et al. Right colon cancer - clinicopathological findings. Chirurgia (Bucur). 2012:107(3):314-24. Romanian

22. Lewis $\mathrm{C}$, Xun P, He K, Effects of adjuvant chemotherapy on recurrence, survival, and quality of life in stage IIcolon cancer patients: a 24-month follow-up. Support Care Cancer. 2016; 24(4):1463-71.

23. Ionilă M, Mărgăritescu C, Pirici D, Mogoantă SS. Mucinous adenocarcinoma of the colon - a histochemical study. Rom J Morphol Embryol. 2011;52(3):783-90.

24. Ueno H, Kajiwara $Y$, Shimazaki $H$, Shinto E, Hashiguchi $Y$, Nakanishi $\mathrm{K}$, et al. New criteria for histologic grading of colorectal cancer. Am J Surg Pathol. 2012;36(2):193-201.

25. Asano H, Kojima K, Ogino N, Fukano H, Ohara Y, Shinozuka N. Postoperative recurrence and risk factors ofcolorectal cancer perforation. Int J Colorectal Dis. 2017;32(3):419-424.

26. Kumar A, Kennecke HF, Renouf DJ, Lim HJ, Gill S, Woods R, et al. Adjuvant chemotherapy useand outcomes of patients with high-risk versus low-risk stage II colon cancer. Cancer. 2015; 121(4):527-34.

27. Otani K, Kawai K, Hata K, Tanaka T, Nishikawa T, Sasaki K, et al. Colon cancer with perforation. Surg Today. 2018 Apr 24. [Epub ahead of print]

28. Wu A, Chen P, Sun T, Wang X, Liu X, Yao Y. Effect of adjuvant chemotherapy on the prognosis of stage II (coloncancer patients with high risk factors, Zhonghua Wei Chang Wai Ke Za Zhi. 2017; 20(12):1381-1386. Chinese

29. Sepulveda AR, Hamilton SR, Allegra CJ, Grody W, CushmanVokoun AM, Funkhouser WK, et al. Molecular Biomarkers for the Evaluation of Colorectal Cancer: Guideline From the American Society for Clinical Pathology, College of American Pathologists, Association forMolecular Pathology, and the American Society of Clinical Oncology. J Clin Oncol. 2017;35(13):1453-1486. 